\title{
DIFFERENTIATED INTEGRATION: PROJECT COMPETITION AND CONTRADICTIONS OFTHE EU INTEGRATION PROCESS
}

\author{
Dmitriy V. Ofitserov-Belskiy \\ Primakov Institute of World Economy and International Relations of the Russian Academy of Sciences, \\ Moscow, Russian Federation
}

\begin{abstract}
Introduction. In 2017 the European Commission proposed five scenarios for the future of the EU, one of which was 'those who want to do more do more'. However, it was not specific enough and ignored the variability of this way of integration. Methods and materials. Ignoring the characteristics of various types of differentiated integration is a common problem in scientific research, which leads to uncertainty and incorrect conclusions. This is largely due to the fact that researchers miss the analysis of interests and the negotiation process, focusing more on finding a common institutional design for all participants of integration. The intergovernmentalism that sees differentiated integration as a special institutional design that helps overcome the impasse in negotiations caused by the growing heterogeneity of member states is lacking. This approach has the potential for research and planning of integration processes in other regions, especially in the Post-Soviet space. Analysis. The article shows that differentiated integration has a long tradition in the EU, but that has little relation to the projects of the European future discussed in recent years (often with the same name). We have focused on the differences in the positions of European governments and groups of countries, trying to explain their motives and to answer the question of whether an intergovernmental approach is justified. The greatest attention is paid to French-German discussions, analysis of the UK's role prior to EU secession, and the special stand of Scandinavian and Central-Eastern European countries. Results. The author concludes that the discussions on differentiated integration are not so much a search for unity in diversity, but are aimed at achieving ambitions, redistributing resources and fight against dirigisme. However, EU reform challenges integration leaders to choose between unprecedented concessions and the need to ignore the positions of many countries. In addition to EU heterogeneity, it also helps to exclude alternatives to differentiation in the future. Since the change of leadership in 2019, the EU has entered a new stage in its development, but there is nothing to suggest that its members are able to find common approaches. For the first time it is not possible to formulate a common compromise out of a wide variety of future options, and an attempt to avoid reform could aggravate the crisis of the integration process.

Key words: integration process theory, differentiated integration, enhanced cooperation, EU, multi-speed Europe, two-speed integration, eurozone, Eurasian integration.

Citation. Ofitserov-Belskiy D.V. Differentiated Integration: Project Competition and Contradictions of the EU Integration Process. Vestnik Volgogradskogo gosudarstvennogo universiteta. Seriya 4. Istoriya. Regionovedenie. Mezhdunarodnye otnosheniya [Science Journal of Volgograd State University. History. Area Studies. International Relations], 2021, vol. 26, no. 5, pp. 202-216. (in Russian). DOI: https://doi.org/10.15688/jvolsu4.2021.5.16
\end{abstract}

УДК 327.7
Дата поступления статьи: 01.06.2020

Дата принятия статьи: 22.01.2021

\section{ДИФФЕРЕНЦИРОВАННАЯ ИНТЕГРАЦИЯ: КОНКУРЕНЦИЯ ПРОЕКТОВ И ПРОТИВОРЕЧИЯ ИНТЕГРАЦИОННОГО ПРОЦЕССА В ЕС}

\author{
Дмитрий Владимирович Офицеров-Бельский \\ Институт мировой экономики и международных отношений им. Е.М. Примакова РАН, \\ г. Москва, Российская Федерация
}

Аннотация. В 2017 г. Еврокомиссия предложила пять вариантов будущего ЕС, одним из которых стал проект дифференцированной интеграции. Однако он не содержал достаточной конкретики и игнорировал 
различия между вариантами такого подхода. Та же проблема нередко наблюдается в научной литературе, что приводит к неопределенности и некорректным выводам. В значительной мере это является следствием того, что исследователи упускают анализ интересов и переговорного процесса, в большей степени сосредотачиваясь на поиске «общего знаменателя» для всех участников интеграции. Этого недостатка лишен межправительственный подход, рассматривающий дифференцированную интеграцию как особый институциональный дизайн, помогающий выйти из тупика переговоров, вызванного растущей неоднородностью государствчленов. Данный подход имеет потенциал для исследования и планирования интеграционных процессов в других регионах мира, особенно на постсоветском пространстве. В статье показано, что дифференцированная интеграция имеет давние традиции в ЕС, но они мало соотносятся с обсуждаемыми в последние годы (зачастую одноименными) проектами европейского будущего. В данной статье мы фокусировали свое внимание на различиях в позициях европейских правительств и групп стран, пытаясь объяснить их мотивы и дать ответ на вопрос об оправданности применения межправительственного подхода. Наибольшее внимание уделено франко-германским дискуссиям, анализу роли Великобритании до выхода из ЕС, а также особой позиции скандинавских и центрально-восточноевропейских стран. Автор приходит к выводу, что дискуссии о дифференцированной интеграции представляют собой не столько поиск единства в разнообразии, сколько нацеленность на реализацию амбиций, перераспределение ресурсов и расширение параметров свободы в отношениях с Брюсселем. Однако необходимость реформирования ЕС ставит лидеров интеграции перед выбором между беспрецедентными уступками и необходимостью игнорировать позиции ряда стран. Наряду с неоднородностью ЕС, это способствует исключению альтернатив дифференциации в будущем. После смены руководства в 2019 г. ЕС вступил в новый этап развития, однако ничто не указывает на то, что его члены способны найти общие подходы. Впервые в новейшей истории Европы из широкого разнообразия вариантов будущего невозможно сформулировать общий компромисс, а попытка отказа от реформирования может усилить кризис интеграционного процесса.

Ключевые слова: теория интеграционного процесса, дифференцированная интеграция, продвинутое сотрудничество, ЕС, многоскоростная Европа, двухскоростная Европа, еврозона, евразийская интеграция.

Цитирование. Офицеров-Бельский Д. В. Дифференцированная интеграция: конкуренция проектов и противоречия интеграционного процесса в ЕС // Вестник Волгоградского государственного университета. Серия 4, История. Регионоведение. Международные отношения. - 2021. - Т. 26, № 5. - С. 202-216. - DOI: https://doi.org/10.15688/jvolsu4.2021.5.16

Введение. Необходимость глубокого пересмотра принципов европейской интеграции была очевидна уже более десяти лет назад, когда в 2007 г. шло обсуждение компромиссного Лиссабонского соглашения. Разработка европейского проекта исторически велась по двум направлениям - по пути глубокой всесторонней интеграции и по пути, который обычно, упрощенно и очень обобщая, именуют концепцией «многих скоростей». Последняя была предложена в 1970-е гг. еврооптимистами, желавшими ускорения интеграции, чему могла помешать неготовность ряда стран к быстрым изменениям. В 1994 г. премьер-министр Франции Э. Балладюр предложил концепцию «концентрических кругов», предполагавшую, что ядро интеграции образуют Франция, Германия и страны Бенилюкса, второй круг составят Великобритания и ряд других стран, не готовых к ускоренным изменениям, в третьем окажутся страны, еще не являющиеся членами Евросоюза [5]. Великобритания выступила тогда против, опасаясь, что за приемлемыми, на первый взгляд, формулировками, скрывается стремление предоставить стране своего рода второстепенное членство [27]. Однако против самой идеи многоскоростной Европы, только не предполагавшей формирования клубов и привилегий для лидеров процесса, Великобритания ничего не имела и впоследствии взяла ее на вооружение. Десятилетие назад с подачи британского премьера Э. Блэра об этом активно заговорили вновь, но уже как о концепции, способной затормозить интеграционный процесс. Именно так концепция многоскоростной Европы стала не совсем справедливо ассоциироваться с евроскептиками.

Поэтапное расширение ЕС привело к тому, что многоскоростная Европа фактически стала реальностью, и в дополнение к скандинавским странам и Великобритании, членами ЕС стали центрально-восточноевропейские страны, которые также не были участниками шенгенской и еврозоны. Противоречия порождались тем, что несмотря на различные 


\section{ИСТОРИЯ МЕЖДУНАРОДНЫХ ОТНОШЕНИЙ}

обязательства по соглашениям, страны ЕС располагали одинаковыми полномочиями касательно будущего объединения в целом. Ключевым же стал вопрос о том, должна ли Европа пытаться сгладить существующие различия, принять их или же целенаправленно проводить политику дифференцированной интеграции в дальнейшем. Иными словами, вопрос перешел в плоскость обсуждения концепций будущего ЕС.

Методы и материалы. Феномен дифференцированной интеграции изучается достаточно давно. Как правило, выделяют три ее варианта - многоскоростную, двухскоростную (переменной геометрии) и a la carte [18; 33; 34; 37]. Существенные содержательные различия между ними долгое время игнорировались и стали очевидными лишь в последние годы, когда вопросы реформирования ЕС приобрели особую дискуссионность. Чаще всего предметом обсуждения становится концепция «двух скоростей», предполагающая углубленную интеграцию на базе еврозоны. Однако, как правило, она также обозначается как интеграция многих скоростей, чтобы предупредить рассуждения о «второсортном» членстве в ЕС и подчеркнуть готовность приветствовать разнообразие подходов. Это приводит к своего рода терминологической неопределенности.

Методологические основы исследований дифференцированной интеграции также не отличаются согласованностью, что вполне естественно, учитывая то, что научные подходы очень часто являются одновременно и политическими, выражая в каждом случае вполне очевидный спектр интересов. Определенные проблемы связаны и с тем, что в экономическом плане интеграция продвинулась существенно дальше, чем в политическом, однако наиболее распространенные методологические подходы хотя и не игнорируют экономическую проблематику, однако имеют очень мало инструментов для ее интерпретации. Сейчас это приобретает особенную актуальность, ввиду того, что одной из наиболее явных европейских тенденций становится слияние политической и экономической повестки.

Наиболее очевидным методологическим решением для изучения дифференцированной интеграции представляется межправительственный подход, наиболее известными представителями которого являются Э. Моравчик и Ф. Шиммельфенниг. Данная теория объясняет европейскую интеграцию как «серию межправительственных сделок» [26], что создает хороший потенциал для анализа кризисных и эмерджентных проявлений интеграционного процесса, а также дифференцированной интеграции, так как во всех этих случаях важнейшее значение приобретает переговорный процесс и торг. Интересно, что до сих пор этот подход практически не применялся для таких целей. Исключение составляет только статья Ф. Шиммельфеннига [30], в которой автор делает лишь попытку обосновать перспективность применения подхода и очень немногочисленные статьи других авторов [17; 35], по сути констатирующих то же, но в более широком контексте методологического поиска. Важно, что подход имеет значительный потенциал экстраполяции и может быть успешно адаптирован для исследования других интеграционных кейсов, в особенности евразийской интеграции.

Существующая литература исходит из почти принятого предположения, что дифференцированная интеграция представляет собой особый институциональный дизайн, помогающий выйти из тупика переговоров, вызванного растущей неоднородностью государствчленов $[14 ; 16 ; 24 ; 32 ; 37]$. Неоднородность государственных предпочтений (отметим, что межправительственный подход избегает использования концепта «национального интереса», а в либеральном варианте не предполагает вообще), зависимостей и возможностей порождает спрос на дифференцированную интеграцию. Однако будет ли действительно реализована дифференцированная интеграция, также зависит от предложения жизнеспособных и взаимовыгодных решений для всех участников дифференциации. Впрочем, Ф. Шиммельфенниг не проводит различий между видами дифференцированной интеграции, что очень ослабляет его подход.

В данной статье мы фокусируем свое внимание на различиях в позициях европейских правительств и отдельных групп стран, пытаясь, с одной стороны, объяснить их мотивы в отстаивании того или иного варианта 
дифференцированной интеграции, а с другой дать ответ на вопрос об оправданности применения межправительственного подхода для ее изучения. Наибольшее значение для понимания применимости подхода и для объяснения причин и путей развития дифференцированной интеграции имеют франко-германские дискуссии, анализ роли Великобритании до выхода из ЕС, а также особая позиция скандинавских и центрально-восточноевропейских стран, которым уделено особенное внимание в данном исследовании.

Дифференцированная интеграция, ставшая характерной чертой европейского объединения на протяжении значительной части его истории, имеет очень мало общего с дифференцированной интеграцией как проектом будущего Европы - они представляют собой не только принципиально разные смыслы и явления, но и в значительной мере противоположны друг другу. Концепция двухскоростной Европы фактически стала вытеснять в интеграционном дискурсе прежнее классическое понимание дифференцированной интеграции, заложенное в европейский проект изначально.

Анализ. У заинтересованных стран были и по-прежнему остаются три опции, позволяющие проводить политику углубленной интеграции. Самая очевидная предполагает создание организаций вне институциональноправовой системы ЕС, примерами чего могут служить Северный совет, Бенилюкс, Европейское космическое агентство и Европейская организация ядерных исследований. Еще одним вариантом является создание «изъятий», то есть исключений из правил для той или иной страны. Подготовка ревизионного договора и его подписание требуют длительного времени и ратификации всеми государствами-членами. Изъятия не могут быть универсальным механизмом еще и потому, что предполагают инициативу и согласие страны, для которой делается исключение из правил. Третий вариант - «продвинутое сотрудничество», представляющее собой процедуру, при которой не менее девяти стран ЕС имеют возможность реализовывать интеграционные проекты и заключать соглашения отдельно от остальных членов. Продвинутое сотрудничество начало реализовываться с 2010 г. и по- степенно стало инструментом решения важных вопросов, по которым затруднителен общий консенсус. Ряд авторов, в частности Л.О. Бабынина, рассматривают данный механизм как новый тренд [1]. Однако в нынешней форме процедуру нельзя считать эффективной, учитывая сложность и продолжительность выработки решений, ввиду множественных оговорок и ограничений, обозначенных в Статье 43 Договора о Европейском Союзе. Наиболее серьезным ограничением является то, что продвинутое сотрудничество не может распространяться «на области, которые являются исключительной компетенцией Сообщества», а это сферы денежной и общей торговой политики, правил конкуренции, таможенного союза и сохранения морских биологических ресурсов. Кроме того, Ниццским договором были определены несколько различные процедуры для разных опор интеграции.

Все перечисленные решения позволяют создавать при необходимости отдельную повестку сотрудничества, но неспособны обеспечить новый импульс интеграции. Наибольшей сложностью в продвижении интеграции сейчас является не отсутствие возможностей сотрудничества в избранных областях, представляющих интерес лишь для части членов $\mathrm{EC}$, а сдерживание дальнейшей интеграции и реформирования институтов отдельными странами ЕС, заставляющими буксовать общеевропейские механизмы. «Речь идет о том, чтобы идти быстрее в кругу некоторых стран, не исключая других, но так, чтобы другие не смогли этому противостоять», - объяснил предыдущий президент Франции Ф. Олланд [28].

В отличие от прочих вариантов Европы многих скоростей, двухскоростная интеграция предполагает существование сильного ядра, сформированного заинтересованными в дальнейшем поступательном сближении странами. Это очень важный аспект, ввиду того, что страны так называемой новой Европы приобрели большой вес при увеличивающейся нелояльности Брюсселю и в целом европейскому проекту. Концепция двухскоростной Европы, по сути, представляет собой инструмент повышения дисциплины и солидарности для одних стран и дискриминационный механизм для других [4]. При этом почти очевидная возможность размежевания Европы активно 


\section{ИСТОРИЯ МЕЖДУНАРОДНЫХ ОТНОШЕНИЙ}

отрицается заинтересованными в таком варианте развития странами ЕС. Критика двухскоростной Европы, в частности со стороны В. Шмидт, также включает тезис о том, что этот концепт не отражает тот факт, что Европа уже является многоскоростной, с государствами-членами, участвующими в различных политических сообществах, и она вряд ли может быть функциональной, учитывая многообразные расхождения в идеях и интересах [31]. Последний тезис представляется принципиально неверным в силу того, что следующие ему авторы не проводят необходимых различий между различными форматами дифференцированной интеграции.

В настоящее время в ЕС происходит формирование своего рода клуба лидеров интеграционного процесса и обсуждается возможность отказа от прежнего либерализма в процессе принятия решений. Их в ближайшие годы предстоит немало - это вопросы полномочий институтов ЕС, общей внешней политики и политики безопасности, европейской армии (пока можно говорить лишь об изменении логики взаимодействия и обеспечении возможности полноценных совместных действий, не используя механизмы НАТО), системы перераспределения ресурсов, изменения миграционной политики, лучшей координации экономической политики в зоне евро, гармонизации налоговой и социальной сферы и др. Накануне саммита в Брюсселе, 6 марта 2017 г. канцлер ФРГ А. Меркель, президент Франции Ф. Олланд и премьер-министры Испании и Италии М. Рахой и П. Джентилони провели встречу в Версале, на которой поддержали концепцию разных скоростей. Саммит в Версале и состоявшаяся на следующий день встреча глав парламентов вышеградских стран в Варшаве фактически олицетворяли раскол между старой и новой Европой.

Практика клубных консультаций о реформировании ЕС становится все более распространенной. Отдельным клубом стала зона валюты евро, которой требуется особая координация экономической политики и решения, отличные от тех, что предназначены для остальных стран. Несовершенство существующей институциональной системы ЕС проявляется в том, что страны еврозоны вправе рассчитывать на то, что остальные члены ЕC не будут иметь голоса в важных для них решениях, однако эти решения влияют на экономические процессы в странах, сохраняющих приверженность национальным валютам. Это становится причиной напряженных дискуссий и стимулирует консультации об ускоренной интеграции зоны евро, наиболее сложным вопросом в которых является минимизация последствий практически неизбежного в этом случае раскола ЕС.

Та же «клубная» тенденция просматривается у периферийных стран ЕС - скандинавских и восточноевропейских. Саммит «Великобритания - Северные и балтийские страны», прошедший в Лондоне 19 и 20 января 2011 г. показал, что в британской внешней политике на тот момент обозначился новый стратегический приоритет - Северная Европа [36]. Из девяти стран-участниц только Финляндия и Эстония являлись членами еврозоны, Норвегия являлась только частью Европейского экономического пространства, а Исландия вела переговоры о присоединении к ЕС, от чего впоследствии решила отказаться. Наряду с вышеградскими странами, североевропейские страны выступали за возможность разных вариаций европейской интеграции в противовес усиливающемуся диктату Брюсселя. Впоследствии, когда была обозначена перспектива выхода Великобритании из ЕС и возникла угроза потери главного выразителя интересов стран, не входящих в зону евро, те же страны посчитали опасной тенденцией стремление к такому формату интеграции, который выведет их на второстепенные роли [22].

С точки зрения межправительственного подхода это можно объяснить тем, что данные страны столкнулись с новыми обстоятельствами переговорного процесса, но, если не вдаваться в множество излишних деталей, объяснение может оказаться существенно проще. Изменились не столько переговорные позиции стран, которые относительно успешно зафиксированы нынешней системой принятия решений в ЕС (в том числе неформальной), а в гораздо большей степени повлияло изменение переговорного дискурса и сопутствующего ему изменения содержания понятий. Для стран, объективно оказавшихся за пределами ряда направлений европейской интеграции, или намеренно принявших решение 
об ограничении своего участия в них, изменилось не только содержание дискуссий, но и возможность повлиять на них. Если прежде речь шла о развитии описанных выше традиционных путей дифференцированной интеграции, то теперь на повестке стоит в большей степени концепция двух скоростей.

Несмотря на то что вопрос реформирования ЕС имеет множество измерений, наиболее содержательное обсуждение дифференцированной интеграции в прошлом десятилетии концентрировалось вокруг экономических вопросов. Это связано с тем, что после сложной ратификации Лиссабонского соглашения начало новой серьезной дискуссии о конфигурации и полномочиях институтов было совершенно неуместным, политические вопросы оказывались слишком чувствительными, а вызовы, связанные с экономическим кризисом, стимулировали работу именно над экономической повесткой.

С началом экономического кризиса, существующий формат ЕС начал восприниматься не как средство решения общих проблем, а как часть этих проблем, и требование реформ стало как никогда острым [13]. Возможность дифференцированной интеграции стала рассматриваться преимущественно через призму судьбы единой валюты, что придало ускорение дискуссиям о реализации концепции «Двух скоростей».

В начале февраля 2011 г. Берлин и Париж предложили принять «Пакт конкурентоспособности», который позволил бы усилить рычаги экономического управления как в странах еврозоны, так и в ЕС в целом. Имитирующее экспромт обсуждение на саммите в Брюсселе началось по инициативе А. Меркель, которую поддержал президент Н. Саркози. Хотя председатель Евросовета Х. Ван Ромпей и глава Еврокомиссии Ж.-М. Баррозу отрицали, что были сделаны какие-либо конкретные предложения, суть инициативы почти сразу стала широко известна. В дополнение к действующему пакту стабильности и роста, определяющему допустимые размеры дефицита государственного бюджета и долга, предлагалось принятие общих оснований для налога на доход корпораций, прекращение системы индексации зарплат в тех странах ЕС, где она существует, увеличение пенсионного возраста, а также конституционное запрещение бюджетных дефицитов. Инициатива не нашла отклика у некоторых стран. Многих насторожило, что предложения были разработаны без участия большинства стран ЕС. В итоге члены валютного блока все же признали необходимость «Пакта конкурентоспособности», но предложили Х. Ван Ромпею подготовить компромиссные предложения к предстоящему 24-25 марта саммиту ЕС [25]. До вынесения проекта на заключение всего Евросоюза было решено обсудить его вновь в формате 17 государств еврозоны.

Фактически это было преамбулой к обсуждению системного реформирования ЕС. В декабре 2011 г., накануне саммита в Брюсселе, президент Н. Саркози и канцлер А. Меркель в письме на имя председателя Евросовета Х. Ван Ромпея представили основные идеи, касающиеся будущего ЕС и призвали сразу после саммита запустить пересмотр базовых соглашений [23]. Франция продемонстрировала едва ли не наибольший энтузиазм в вопросе реформирования, предоставив председателю Евросовета лишь возможность реагировать на озвученные инициативы.

Детальный план «На пути к подлинному экономическому и валютному союзу» был представлен Х. Ван Ромпеем в июне 2012 г. на фоне разрастания греческого долгового кризиса [15]. План содержал оговорки, призванные ослабить возможную критику со стороны стран, в зону евро не входящих: «Видение будущего управления Экономического и валютного союза, изложенное в настоящем докладе, сосредоточено на государствах членах зоны евро, поскольку они качественно отличаются от прочих стран в силу единой валюты. Тем не менее, процесс углубления экономического и валютного союза должен характеризоваться открытостью и прозрачностью и быть полностью совместим с единым рынком во всех аспектах» [15]. План предполагал создание европейского казначейства для контроля за исполнением общеевропейского бюджета, европейского банковского регулятора и единой схемы гарантии банковских депозитов. Для его реализации отводилось десять лет и столь длительный срок заставлял прислушаться к мнению скептиков, посчитавших этот план несбыточным. 


\section{ИСТОРИЯ МЕЖДУНАРОДНЫХ ОТНОШЕНИЙ}

Вскоре, в ноябре 2012 г. Ж.-М. Баррозу выступил с пакетом предложений для еврозоны и для ЕС, продолжавших логику плана $\mathrm{X}$. Ван Ромпея [2] Он заявил, что «зона евро должна интегрироваться быстрее и глубже, чем ЕС в целом», но предостерег относительно двухскоростной Европы. В числе предложений было создание фонда, к помощи которого могли бы прибегать страны, нарушающие нормативы дефицита бюджета и государственного долга. Ж.-М. Баррозу предлагал до 2018 г. в рамках Еврокомиссии создать Министерство финансов, имеющее полномочия налагать вето и требовать внесения поправок в национальные бюджеты. Важной инновацией, отличавшей план Ж.-М. Баррозу от плана $\mathrm{X}$. Ван Ромпея, было заявление о создании единого бюджета еврозоны [19]. Несмотря на оппозицию Германии, план предполагал выпуск совместных облигаций стран зоны евро (в плане Х. Ван Ромпея такое предложение тоже присутствовало). Примечательно, что Ж.-М. Баррозу выдвигал обозначенный план уже как пятилетний, то есть налицо была попытка ускорить процесс трансформации ЕC.

Все перечисленные проекты неизбежно должны были негативно сказаться на позициях Великобритании и, по всей видимости, это предусматривалось изначально с целью ее изоляции от процесса принятия решений. Планы не были согласованы со страной, являющейся членом «большой тройки», что скандально само по себе, тем более что они должны были затронуть интересы Лондона в большей степени, нежели других европейских столиц. Поэтому неудивительно, что вскоре после обнародования первоначального плана Х. Ван Ромпея, 15 мая 2012 г. впервые прозвучало слово Brexit [39], а уже в конце июня 2012 г. перспективу выхода из ЕС на официальном уровне не исключал и премьер-министр Д. Кэмерон [11]. Выступление британского премьера состоялось сразу после окончания саммита ЕС и через три дня после обнародования детализированного плана Х. Ван Ромпея. Очевидно, что Великобританию вполне целенаправленно «выдавливали» из ЕС, постепенно сводя ее роль в объединении до уровня второстепенной страны. Полностью очевидным это стало во время выборов главы Еврокомиссии - кандидатура Ж.-К. Юн- кера не была согласована с Лондоном и принята по настоянию А. Меркель вопреки возражениям британцев.

До прихода Ж.-К. Юнкера на пост главы Еврокомиссии практические разработки реформирования ЕС в духе дифференцированной интеграции велись именно в Брюсселе и согласовывались с франко-германским тандемом или же «большой четверкой» еврозоны. Публичная инициатива исходила попеременно от глав Еврокомиссии и Евросовета. В отличие от предшественников, Ж.-К. Юнкер был гораздо более самостоятелен в своих действиях и значительно больше занимался продвижением ведомственных интересов Еврокомиссии. Он был негативно настроен относительно любых моделей, предполагавших внутреннее размежевание в Европе и различия в обязательствах участников интеграции, что принципиально не соответствовало его убеждениям и плохо гармонировало с инициативами, направленными на концентрацию власти в руках Еврокомиссии. Соответственно, Ж.-К. Юнкер тормозил любые разработки проектов дифференцированной интеграции, по причине чего соответствующие дискуссии переместились из Брюсселя в европейские столицы.

Тем не менее в марте 2017 г. главой Европейской комиссии была предложена к обсуждению «Белая книга» о будущем Европы после Брексит. В предложенных пяти вариантах содержалась основа для возвращения обсуждения к более общим основаниям - к дискуссии не только о дифференцированной интеграции, которая уже практически становится реальностью, но и о других возможных вариантах. Создается впечатление, что «Белая книга» была специально подготовлена таким образом, чтобы не дать ответы, а усилить уже имеющиеся дискуссии. В этом смысле маневр Ж.-К. Юнкера получился одновременно упреждающим инициативы европейских правительств в этой сфере и компромиссным, поскольку идеи разноскоростной Европы были все же изложены. Дискуссионность документа оказалась недооценена, и вскоре после того, как он был представлен, практически все наблюдатели сошлись во мнении, что в такой завуалированой форме была фактически предложена только одна концепция многоскорост- 
ной Европы [7; 9]. Причиной такой трактовки стала последовавшая 6 марта 2017 г. встреча глав государств «большой четверки» в Версале, а точнее - принятые на ней решения, в которых приверженность идее многоскоростной Европы была определена открыто.

В среде европейской бюрократии любые вариации разноскоростной Европы рассматриваются либо негативно, либо как возможный выбор для стран, злоупотребляющих приверженностью собственной позиции по ряду вопросов, но при этом закономерно опасающихся оказаться на обочине европейской интеграции. Наибольшие опасения связаны с потенциалом дезинтеграции, который несут в себе все варианты дифференцированной интеграции, хотя существует целый ряд новейших исследований, авторы которых склонны не противопоставлять интеграцию и дезинтеграцию, а рассматривать их как процессы, которые могут одновременно идти на одном политическом пространстве [12; 38].

В Еврокомиссии понимают, что, если дело дойдет до реализации концепции, это будет амбивалентная ситуация, при которой не только ослабнет голос немалого количества стран ЕС, но и влияние Брюсселя на их политику (и без того слабое сейчас) станет пренебрежимо малым. Лояльность ЕС со стороны стран-членов снижается, даже если говорить о лидерах европейской интеграции. Выход Великобритании из ЕС, демонстративное противостояние с Берлином и Брюсселем восточноевропейских стран, политико-экономические последствия пандемии 2020 г. - все это явные проявления потери общих ориентиров и кризиса ЕC.

Брексит стал для европейского проекта стресс-тестом и отправной точкой для поиска новых решений. Заявление Великобритании о готовности покинуть ЕС не только актуализировало вопрос о реформировании союза [8], но и укрепило решимость европейских столиц и бюрократии продвигать собственную повестку. Особенно заметно это по политике Франции, которая активизировалась в своем стремлении к европейскому лидерству.

Серьезный сдвиг наметился и в европейской политической культуре. Наряду с ослаблением готовности к консенсусу, среди европейских политиков усиливается сомнение в демократии и плюрализме, как базовых ценностях европейской интеграции. Во многом это связано с тем, что Брексит стал возможен именно вследствие референдума, а опасность прихода популистов к власти в ряде стран Европы в 2017 г. только усилила сомнение. Разумеется, речь не идет о тотальной переоценке ценностей, однако следствием стала готовность к отказу от принципа единогласия при решении ключевых вопросов интеграции, понимание необходимости упрощения системы введения внутренних санкций, логика предоставления средств из европейских фондов в обмен на лояльность и торможение обсуждения планов введения прямых выборов главы Еврокомиссии. Все это становится предпосылкой или косвенно способствует интеграции по пути многих скоростей.

Оживление в дальнейшее обсуждение реформирования ЕС привнесло избрание президентом Франции Э. Макрона, вскоре анонсировавшего ряд предполагаемых изменений, которые во многом были развитием предложений, озвученных еще его предшественниками. Французская модель будущего Европы означает консолидацию еврозоны, даже ценой наращивания экономической дистанции и противоречий с прочими странами. Прежде действительно можно было говорить о том, что страны общей валюты наиболее лояльны европейскому проекту и поэтому отдельно от остальных способны достичь скорейшего прогресса в интеграции. Однако нарастающие экономические проблемы южноевропейских стран и рост евроскептических настроений именно в странах еврозоны ставят этот тезис под сомнение. Тем не менее, Франция продолжает настаивать на обсуждении концепции «многих скоростей» именно в этой интерпретации.

Важной инициативой французского президента является идея создания Министерства финансов еврозоны, с функциями европейского комиссара по экономическим и финансовым вопросам и главы Еврогруппы министров финансов стран ЕС для его руководителя. По мнению Э. Макрона, он мог бы распоряжаться общей многомиллиардной казной стран еврозоны и осуществлять инвестиции в совместные проекты. Координация финансовой политики обсуждается давно, но все 


\section{ИСТОРИЯ МЕЖДУНАРОДНЫХ ОТНОШЕНИЙ}

более ранние предложения предполагали создание министерства финансов ЕС, а не еврозоны. Помимо этого, Э. Макрон озвучил предложение по формированию единого бюджета еврозоны с возможностью займов и превращения стабилизационного механизма в Европейский валютный фонд. Из общего фонда в случае нового кризиса можно было бы предоставлять помощь попавшим в затруднительное положение странам еврозоны. Без такого финансового перераспределения, по мнению Э. Макрона, валютный союз когданибудь прекратит существование, так же как придет конец и объединенной Европе. Кроме того, французский президент поддерживает планы по созданию отдельного парламента стран еврозоны [29]. «Отдельный бюджет означает также отдельный парламент еврозоны (дословно - Euroland), чтобы евродепутаты из стран зоны контролировали этот бюджет», считает бывший еврокомиссар по финансовым вопросам П. Московиси [20]. Европейский проект давно подвергается критике за то, что политическая интеграция очень серьезно отстала от экономической части.

Германский взгляд на перспективу создания министерства финансов еврозоны и на другие смелые инициативы принципиально иной. В Германии резко возражают против выпуска единых облигаций государственного займа, за которые ратует Э. Макрон, отвечать по которым должны были бы сообща все страны еврозоны. Это позволило бы отдельным странам, в частности Италии и самой Франции, брать займы на долговых рынках под более низкий процент, что снизило бы нагрузку на бюджеты. Однако В. Шойбле, а теперь и его преемник на посту министра финансов ФРГ О. Шольц, неизменно пресекали любые разговоры на эту тему, опасаясь, что «партнеры Германии наберут дешевых кредитов, а отдуваться придется налогоплательщикам», то есть той же Германии [3].

В Берлине готовы с определенными оговорками инвестировать как в европейское единство, так и в укрепление собственного доминирования в Европе, тем более что до сих пор это были связанные подходы. Однако французские предложения несут в понимании немецких политиков большие риски для единства Европы и лидерства Германии, одновре- менно налагая на нее избыточные обязательства. К тому же позиции христианских демократов ослабли после выборов 2017 г., а их союзники по коалиции, как и политические конкуренты, настроены скептически либо к такой роли, либо к необходимости помогать кризисным экономикам еврозоны. Профсоюзы и часть бизнеса также против европейского единства, ценой которому станет нагрузка на германский бюджет.

Из всех вариантов Европы многих скоростей, возможность углубленной интеграции еврозоны проработана наиболее последовательно, но она же является наиболее дискуссионной. Французские политики длительное время выступают сторонниками двухскоростного подхода в сфере экономики и институциональной системы ЕС, но одновременно стремятся к консолидированной внешней и оборонной политике. Это связано с тем, что в экономическом смысле Франция уже существенно отстает от Германии, а в военном отношении, после выхода Великобритании из $\mathrm{EC}$, становится лидирующей силой и единственной ядерной державой в объединении. Несмотря на то что сила и репутация Германии, по всей вероятности, будут и дальше укрепляться, она останется, в лучшем случае, «неохотным гегемоном» [10]. Все это, наряду с Брекситом, создает предпосылки как для реализации французского подхода, так и для усиления всеевропейского значения франкогерманского тандема [21].

Противоречия и недосказанность, присутствующие в проектах дифференцированной интеграции, дали возможность прежнему главе Еврокомиссии Ж.-К. Юнкеру использовать как консерватизм германского канцлера, которая сомневается в необходимости ускоренных преобразований в данном направлении, так и энтузиазм французского лидера, вызывающий закономерные опасения в ряде стран, главным образом в тех, что еще не присоединились к зоне евро и Шенгенскому соглашению. Брюссельская бюрократия воодушевлена Э. Макроном, хотя и полагает, что большая часть его предложений встретит сопротивление и нереализуема, однако может послужить хорошим катализатором изменений. В частности, в Еврокомиссии периода председательства Ж.-К. Юнкера считали, что 
предложения о создании отдельного бюджета еврозоны и Европейского Валютного Фонда необходимо рассматривать после углубления экономического и валютного союза: «Это возможно, скорее, в долгосрочной перспективе, учитывая общий бюджет ЕС и растущее в будущем количество стран, которые примут единую валюту» [20]. Иными словами, позиция Еврокомиссии представляла собой вежливую форму отказа и с тех пор мало что принципиально изменилось.

В палитре подходов к реформированию ЕС не наблюдается ни согласия, ни последовательности. В июне 2018 г. на саммите ЕС планировалось обсуждение концепций супергосударства Ж.-К. Юнкера и двухскоростной Европы Э. Макрона, однако этого не произошло. Вместо конкретных планов можно было наблюдать лишь риторику о сильной и независимой Европе. Привычные постулаты о необходимости создания единой европейской армии звучали почти синхронно с заявлениями о возможности сокращения количества стран-участниц Шенгенского договора [6].

Смена глав европейских институтов в 2019 г. не привела к перезагрузке обсуждений, не добавила им конкретики и содержательности. Ничто не указывает на то, что новое руководство Еврокомиссии имеет собственное видение будущего ЕС. Вопросы реформирования находятся преимущественно в сфере ответственности вице-президентов М. Шефчовича, Д. Шуицы и В. Юровой. Их выбор мотивирован не столько профессиональным опытом (за исключением М. Шефчовича, занимавшего должность европейского комиссара по междуинституциональным отношениям и администрации в 2010-2014 гг.), сколько политическими соображениями - все трое представляют «новую» Европу, от которой ожидаемо сопротивление реформам. Неясна и степень заинтересованности в реформировании институтов, учитывая, что новый президент Еврокомиссии У. фон дер Ляйен обозначила ее как геополитическую, тем самым указывая на другие приоритеты.

Предполагается, что основной дискуссионной площадкой с лета 2020 г. должна стать Конференция о будущем Европы, которая будет работать последующие два года, особая ответственность за проведение которой воз- ложена на вице-президента Еврокомиссии Д. Шуицу, не имеющую опыта работы с конституционными вопросами ЕС. В процедурной логике конференции ясно просматриваются черты демократического популизма, при этом, решения будут иметь рекомендательный характер. Поэтому следует полагать, что на практике конференция обернется лишь имитацией демократического процесса.

Результаты. Реформирование ЕС, как и прежде, предполагает обязательное согласование интересов ведущих европейских столиц. Однако дискуссии о дифференцированной интеграции направлены не столько на совершенствование институтов и практик, сколько служат реализации амбиций, попыткам перераспределения ресурсов и расширения параметров свободы в отношениях с Брюсселем.

Сейчас ситуация нова тем, что необходимость реформирования ЕС ставит лидеров интеграции перед выбором между беспрецедентными уступками и необходимостью игнорировать позиции ряда стран. Наряду с неоднородностью ЕС, это также способствует исключению альтернатив дифференциации в будущем, представляющей, как было отмечено ранее, несколько разных по сути подходов. Все это вполне соответствует интерпретационной логике межправительственного подхода. Европейский опыт в данных аспектах важен тем, что ставит вопросы, связанные с гармонизацией интересов на очень развитом уровне интеграции. Таким образом, он позволяет прогнозировать вызовы, в перспективе неизбежные для других сообществ особенно для ЕАЭС, который, с большой вероятностью, также ожидает дифференцированное будущее (особенную глубину может обрести российско-белорусская интеграция).

Коллизия нынешней ситуации в ЕC coстоит в том, что, пожалуй, впервые из всех имеющихся вариантов невозможно синтезировать общий компромиссный подход, а попытка обойтись полумерами может оказаться очень дорогой. До тех пор, пока не удастся преодолеть слабость европейских институтов, переговоры европейских держав, не охватывающие все страны, что почти невозможно успешно провести в нынешних условиях, дадут лишь негативный эффект для европейской интеграции, вне зависимости от того, ка- 


\section{ИСТОРИЯ МЕЖДУНАРОДНЫХ ОТНОШЕНИЙ}

кие решения будут приняты и будут ли они приняты вообще.

\section{СПИСОК ЛИТЕРАТУРЫ}

1. Бабынина, Л.О.Применение продвинутого сотрудничества - новый тренд развития Европейского Союза / Л. О. Бабынина // Вестник МГИМО Университета. - 2014. - № 4 (37). - С. 148-154.

2. Баррозо представил план перестройки ЕС. Электрон. текстовые дан. - Режим доступа: https:// www.dw.com $/ \mathrm{ru} / \% \mathrm{D} 0 \% \mathrm{~B} 1 \% \mathrm{D} 0 \% \mathrm{~B} 0 \% \mathrm{D} 1 \% 80 \% \mathrm{D} 1 \%$ $80 \% \mathrm{D} 0 \% \mathrm{BE} \% \mathrm{D} 0 \% \mathrm{~B} 7 \% \mathrm{D} 1 \% 83-\% \mathrm{D} 0 \% \mathrm{BF} \% \mathrm{D} 1 \%$ $80 \% \mathrm{D} 0 \% \mathrm{~B} 5 \% \mathrm{D} 0 \% \mathrm{~B} 4 \% \mathrm{D} 1 \% 81 \% \mathrm{D} 1 \% 82 \% \mathrm{D} 0 \% \mathrm{~B} 0 \%$ D0\%B2\%D0\%B8\%D0\%BB-\%D0\%BF\%D0\%BB\% D0\%B0\%D0\%BD-\%D0\%BF\%D0\%B5\%D1\%80\% D0\%B5\%D1\%81\%D1\%82\%D1\%80\%D0\%BE\% D0\%B9\%D0\%BA\%D0\%B8-\%D0\%B5\%D1\%81/a16415068 (дата обращения: 02.05.2020). - Загл. с экрана.

3. Берлин и Париж на пороге перезагрузки отношений. - Электрон. текстовые дан. - Режим доступа: https://www.dw.com/ru/\%D0\%B1\%D0\% B5\%D1\% $80 \% \mathrm{D} 0 \% \mathrm{BB} \% \mathrm{D} 0 \% \mathrm{~B} 8 \% \mathrm{D} 0 \% \mathrm{BD}-\% \mathrm{D} 0 \% \mathrm{~B} 8-$ $\% \mathrm{D} 0 \% \mathrm{BF} \% \mathrm{D} 0 \% \mathrm{~B} 0 \% \mathrm{D} 1 \% 80 \% \mathrm{D} 0 \% \mathrm{~B} 8 \% \mathrm{D} 0 \% \mathrm{~B} 6$ $\% \mathrm{D} 0 \% \mathrm{BD} \% \mathrm{D} 0 \% \mathrm{~B} 0-\% \mathrm{D} 0 \% \mathrm{BF} \% \mathrm{D} 0 \% \mathrm{BE} \% \mathrm{D} 1 \%$ $80 \%$ D $0 \%$ BE $\%$ D0 $\%$ B3\%D0\%B5-\%D0\%BF\% D0\%B5\%D1\%80\%D0\%B5\%D0\%B7\%D0\%B0\% $\mathrm{D} 0 \% \mathrm{~B} 3 \% \mathrm{D} 1 \% 80 \% \mathrm{D} 1 \% 83 \% \mathrm{D} 0 \% \mathrm{~B} 7 \% \mathrm{D} 0 \% \mathrm{BA} \% \mathrm{D} 0 \% \mathrm{~B} 8-$ $\%$ D $0 \%$ B E \% D $1 \% 82 \%$ D $0 \%$ B D \% D 0 \% B E \% D1\%88\%D0\%B5\%D0\%BD\%D0\%B8\%D0\%B $\% / a-$ 38844105 (дата обращения: 02.05.2020).-Загл. с экрана.

4. Марков, Г. В. «Европа многих скоростей»: проблемы эволюции геокультурной интеграции / Г. В. Марков, Б. В. Салихов // Регионология. 2020. -№1. -C. 10-27. - DOI: 10.15507/2413-1407.110. 028.202001.010-027.

5. Порецкова, Е. А. Концепция «многоскоростной» Европы в стратегии консервативного кабинета Дж. Мейджора / Е. А. Порецкова // Известия Тульского государственного университета. Гуманитарные науки. - 2011. - № 2. - С. 327-333. - Электрон. текстовые дан. - Режим доступа: https:// cyberleninka.ru/article/n/kontseptsiyam nog oskorostnoy-evropy-v-strategi konservativnogo-kabineta-dzh-meydzhora (дата обращения: 02.05.2020). - Загл. с экрана.

6. Annonces de Macron: vote blanc, référendum, services publics... Ce qu'il faut retenir. Electronic text data. - Mode of access: https:// www.lemonde.fr/politique/article/2019/04/25/voteblanc-et-ric-ecartes-baisses-d-impots-ce-qu-il-fautretenir-de-la-conference-de-presse-de-macron 5454978 823448.html (date of access: 02.05.2020). Title from screen.
7. Bebel, J. Central Europe's Multispeed Dilemma / J. Bebel. - Electronic text data. - Mode of access: https://www.europeaninstitute.org/index.php/ei-blog/ 302-june-2017/2228-central-europe-s-multispeeddilemma-6-12 (date of access: 02.05.2020). - Title from screen.

8. Brexit: History, Reasoning and Perspectives / D. Ramiro Troitiño, T. Kerikmäe, A. Chochia. - L. : SpringerLink, 2018. -300 p.- DOI: 10.1007/978-3-31973414-9.

9. Brussels Draws Up Plans for More 'MultiSpeed' Post-Brexit EU-27. - Electronic text data. Mode of access: https://www.ft.com/content/c56f99defdda-11e6-8d8e-a5e3738f9ae4 (date of access: 02.05.2020). - Title from screen.

10. Bulmer, S. Germany As the EU's Reluctant Hegemon? Of Economic Strength and Political Constraints / S. Bulmer, W. E. Paterson // Journal of European Public Policy. - 2013. - № 20 (10). - P. 13871405.-DOI: 10.1080/13501763.2013.822824.

11. Cameron Defies Tory Right Over EU Referendum. Prime Minister, Buoyed by Successful Negotiations on Eurozone Banking Reform, Rejects «in or out» Referendum on EU. - Electronic text data. Mode of access: https://www.theguardian.com/ politics/2012/jun/29/cameron-no-eu-referendum (date of access: 02.10.2020). - Title from screen.

12. Chopin, T. Differentiation As a Double-Edged Sword: Member States' Practices and Brexit / T. Chopin, C. Lequesne// International Affairs. - 2016. - Vol. 92, no. 3. - P. 531-545.

13. Cini, M. European Union Politics / M. Cini, N. Pérez-Solórzano Borragán. - Oxford : Oxford University Press, 2016. - 471 p. - DOI: 10.1093/hepl/ 9780198806530.001 .0001 .

14. Dyson, K. Differentiation As Design Principle and As Tool in the Political Management of European Integration: Which Europe? / K. Dyson, A. Sepos. Basingstoke : Palgrave, 2010. - P. 3-23.

15. European Council Herman Van Rompuy. Brussels, 26 June 2012 EUCO 120/12 PRESSE 296 PR PCE 102. - Electronic text data. - Mode of access: https:/ /www.consilium.europa.eu/media/21570/131201.pdf (date of access: 02.10.2020). - Title from screen.

16. Holzinger, K. EU Environmental Policy in the Joint-Decision Trap? The Critical Balance Between Negative and Positive Integration: Exits from the JointDecision Trap: Comparing EUPolicies/ ed.by G. Falkner. Oxford : Oxford University Press, 2011. - P. 110-127.

17. Holzinger, K. Differentiated Integration in the European Union Many Concepts, Sparse Theory, Few Data / K. Holzinger, F. Schimmelfennig // Journal of European Public Policy. - 2012. - Vol. 19, iss. 2. P. 292-305.-DOI: 10.1080/13501763.2012.641747.

18. Jensen, C. B. The Politics of Multispeed Integration in the European Union. European Union: 
Power and policy-making / C. B. Jensen, J. B. Slapin / ed. by J. Richardson, S. Mazey. - London : Routledge, 2015. - P. 63-80. - DOI: 10.4324/9781315735399.

19. José Manuel Durão Barroso, President of the European Commission. Presentation of European Commission Work Programme 2012 SPEECH/11/755, European Parliament. Strasbourg, 15 Nov. 2011. Electronic text data. - Mode of access: http:/europa. eu/rapid/press-release SPEECH-11-755 en.htm (date of access: 02.05.2020). - Title from screen.

20. Komisarz UE: strefa euro potrzebuje własnego parlamentu. - Electronic text data. - Mode of access: http://biznes.onet.pl/wiadomosci/ue/parlamenteurolandu-jesli-powstanie-budzet-strefy-euromoscovici/hszb3g (date of access: 02.05.2020). - Title from screen.

21. Krotz, U. Back to the future? Franco-German bilateralism in Europe's post-Brexit union / U. Krotz, J. Schild // Journal of European Public Policy. - 2018. Vol. 25, iss. 8. - P. 1174-1193. -DOI: 10.1080/13501763. 2018.1467951.

22. Lang, K.-O. Die Visegrád-Staaten und der Brexit: im östlichen Mitteleuropa herrscht Sorge angesichts des britischen EU-Austritts / K.-O. Lang // SWP-Aktuell. - 2016. - No. 53. - P. 1-4. - Electronic text data. - Mode of access: https://www.ssoar.info/ ssoar/bitstream/handle/document/47800/ssoar-2016lang-Die_Visegrad-Staaten_und_der_Brexit.pdf; jsessionid $=287$ A729186FBD560B08CF269D575F6BB? sequence $=1$ (date of access: 02.05 .2020$)$. - Title from screen.

23. Lettre commune de m. Nicolas Sarkozy, Président de la République, et mme Angela Merkel, Chancelière de la République Fédérale d'Allemagne, adressée à $\mathrm{m}$. Herman van Rompuy, Président du Conseil Européen, sur les mesures en faveur du renforcement de la zone euro, le 7 décembre 2011. 7 décembre 2011. - Electronic text data. - Mode of access: https://www.elysee.fr/nicolas-sarkozy/2011/ 12/07/lettre-commune-de-m-nicolas-sarkozypresident-de-la-republique-et-mme-angela-merkelchanceliere-de-la-republique-federale-dallemagneadressee-a-m-herman-van-rompuy-president-duconseil-europeen-sur-les-mesures-en-faveur-durenforcement-de-la-zon (date of access: 02.05.2020). Title from screen.

24. Majone, G. Europe As the Would-Be World Power. The EU at Fifty / G. Majone. - Cambridge : Cambridge University Press, 2009. - 266 p.

25. Merkel, Sarkozy Outline Competitiveness Pact. Electronic text data. - Mode of access: https:// www.politico.eu/article/merkel-sarkozy-outlinecompetitiveness-pact/ (date of access: 02.05.2020). Title from screen.

26. Moravcsik, A. Preferences and Power in the European Community. A Liberal Intergovernmentalist
Approach / A. Moravcsik // Journal of Common Market Studies. - 1993. - No. 31 (4). - P. 473-524.

27. Mr Major's Speech in Leiden. - 1994. Sep. 7. - Electronic text data. - Mode of access: http:/ /www.iohnmaior.co.uk/page1124.html (date of access: 02.05.2020). - Title from screen.

28. Niemcy popierają Europę dwóch prędkości.Electronic text data. - Mode of access: http:// www.newsweek.pl/swiat/europa-dwoch-predkosci, artykuly,406496,1.html (date of access: 02.05.2020).Title from screen.

29. Réformes de la zone euro: pourquoi la réunion entre Macron et Merkel à Berlin est cruciale. Electronic text data. - Mode of access: https:// www.lemonde.fr/europe/article/2018/04/19/reformesde-la-zone-euro-pourquoi-la-reunion-entre-macron-etmerkel-a-berlin-est-cruciale_5287737_3214.html(date of access: 02.05.2020). - Title from screen.

30. Schimmelfennig, F. The Choice for Differentiated Europe: An Intergovernmentalist Theoretical Framework / F. Schimmelfennig // Comparative European Politics. - 2019. - February. P. 176-191. - DOI: 10.1057/s41295-019-00166-5.

31. Schmidt, V. The Future of Differentiated Integration: A 'Soft-Core' Multi-Clustered Europe of Overlapping Policy Communities / V. Schmidt //Comparative European Politics. -2019. - Vol. 17, iss. 2. P. 294-315.-DOI: 10.1057/s41295-019-00164-7.

32. Stubb, A. The 1996 Intergovernmental Conference and the Management of Flexible Integration / A. Stubb // Journal of European Public Policy. - 1997. No. 4 (1).-P. 37-55. - DOI: 10.1080/135017697344226. 33. Stubb, A. A Categorization of Differentiated Integration / A. Stubb // Journal of Common Market Studies. - 1996. - No. 34 (2). - P. 283-295. - DOI: 10.1111/j.1468-5965.1996.tb00573.x.

34. Stubb, A. Negotiating Flexibility in the European Union: Amsterdam, Nice and Beyond / A. Stubb. - L. : Palgrave MacMillan, 2002.-XIV.-218p.-DOI: 10.1057/ 9781403907615.

35. Tosiek, P. Scenariusze rozwoju Unii Europejskiej w ujęciu liberalnej międzyrządowości. Integracja Europejska - Polska perspektywa / P. Tosiek // Warszawa: Wydawnistwo sejmowe, 2018. - P. 283-303.

36. Towards a Genuine Economic and Monetary Union. Report by President of the Why Nordic Countries are a Cornerstone of British Foreign Policy. Electronic text data. - Mode of access: http:// www.nouvelle-europe.eu/en/why-nordic-countriesare-cornerstone-british-foreign-policy (date of access: 02.10.2020). - Title from screen.

37. Warleigh, A. Flexible Integration: Which Model for the European Union? / A. Warleigh. - L. : Sheffield Academic Press, 2002. - 144 p.

38. Webber, D. Trends in European political (Dis)Integration. An Analysis of Postfunctionalist and 
other explanations / Webber D. // Journal of European Public Policy. - 2019. - Vol. 26, iss. 8: Special Issue: Re-Engaging Grand Theory: European Integration in the Twenty-First Century. - P. 1134-1152. - DOI: 10.1080/13501763.2019.1576760.

39. Wilding, P. Stumbling Towards the Brexit. Britain, a Referendum and an Ever-Closer Reckoning / P. Wilding. - Electronic text data. - Mode of access: https://blogactiv.eu/blog/2012/05/15/stumblingtowards-the-brexit/ (date of access: 02.05.2020). - Title from screen.

\section{REFERENCES}

1. Babynina L.O. Primenenie prodvinutogo sotrudnichestva - novyj trend razvitiya Evropejskogo Soyuza [The Application of Advanced Cooperation A New Trend in the Development of the European Union]. Vestnik MGIMO-Universiteta [Bulletin of the MGIMO University], 2014, no. 4 (37), pp. 148-154.

2. Barrozo predstavil plan perestrojki ES [Barroso Presented the EU's Restructuring Plan]. URL: https://www.dw.com/ru/\%D0\%B1\%D0\%B0\%D1\% $80 \%$ D1\%80\%D0\%BE\%D0\%B7\%D1\%83-\%D0\% BF\%D1\%80\%D0\%B5\%D0\%B4\%D1\%81\%D1\%82\%D0\% B0\%D0\%B2\%D0\%B8\%D0\%BB-\%D0\%BF\%D0\% BB\%D0\%B0\%D0\%BD-\%D0\%BF\%D0\%B5\%D1\% $80 \%$ D0 \%B $5 \%$ D1\%81\%D1\%82\%D1\%80\%D0\% BE\%D0\%B9\% D0\%BA\%D0\%B8-\%D0\%B5\%D1\%81/ a-16415068 (accessed 2 May 2020).

3. Berlin i Parizh na poroge perezagruzki otnoshenij [Berlin and Paris are on the Verge of a Reset of Relations]. URL: https://www.dw.com/ru/\%D0\% B1\%D0\%B5\%D1\%80\%D0\%BB\%D0\%B8\%D0\%BD$\% \mathrm{D} 0 \% \mathrm{~B} 8-\% \mathrm{D} 0 \% \mathrm{BF} \% \mathrm{D} 0 \% \mathrm{~B} 0 \% \mathrm{D} 1 \% 80 \% \mathrm{D} 0 \% \mathrm{~B} 8 \%$ D0\%B6-\%D0\%BD\%D0\%B0-\%D0\%BF\%D0\% BE $\%$ D $1 \% 80 \%$ D $0 \%$ BE $\%$ D $0 \%$ B $3 \%$ D 0\%B $5-$ $\% \mathrm{D} 0 \% \mathrm{BF} \% \mathrm{D} 0 \% \mathrm{~B} 5 \% \mathrm{D} 1 \% 80 \% \mathrm{D} 0 \% \mathrm{~B} 5 \% \mathrm{D} 0 \% \mathrm{~B} 7 \%$ D0\%B0\%D0\%B3\%D1\%80\%D1\%83\%D0\%B7\%D0\% BA $\%$ D0\%B8-\%D0\%BE\%D1\%82\%D0\%BD\%D0\% $\mathrm{BE} \% \mathrm{D} 1 \% 88 \% \mathrm{D} 0 \% \mathrm{~B} 5 \% \mathrm{D} 0 \% \mathrm{BD} \% \mathrm{D} 0 \% \mathrm{~B} 8 \% \mathrm{D} 0 \% \mathrm{~B} 9 / \mathrm{a}-$ 38844105 (accessed 2 May 2020).

4. Markov G.V., Salihov B.V. «Evropa mnogih skorostej»: problemy evolyucii geokul'turnoj integracii ["Multi-Speed Europe": Problems of the Evolution of Geocultural Integration]. Regionologia [Regionology], 2020, no. 1, pp. 10-27. DOI: 10.15507/2413-1407.110.028. 202001.010-027.

5. Poreckova E.A. Koncepciya «mnogoskorostnoj» Evropy v strategii konservativnogo kabineta Dzh. Mejdzhora [The Concept of "Multi-Speed" Europe in the Strategy of the Conservative Government of J. Major]. Izvestiya Tul'skogo gosudarstvennogo universiteta. Gumanitarnye nauki [Izvestiya Tula State University. Humanitarian Sciences], 2011, pp. 327-
333. URL: https://cyberleninka.ru/article/n/ kontseptsiya-mnogoskorostnoy-evropy-v-strategiikonservativnogo-kabineta-dzh-meydzhora (accessed 2 May 2020).

6. Annonces de Macron: vote blanc, référendum, services publics... Ce qu'il faut retenir. URL: https://www.lemonde.fr/politique/article/2019/04/ 25/vote-blanc-et-ric-ecartes-baisses-d-impots-ce-quil-faut-retenir-de-la-conference-de-presse-demacron_5454978_823448.html (accessed 2 May 2020).

7. Bebel J. Central Europe's Multispeed Dilemma. URL: https://www.europeaninstitute.org/ index.php/ei-blog/302-june-2017/2228-central-europes-multispeed-dilemma-6-12 (accessed 2 May 2020).

8. Ramiro Troitiño D., Kerikmäe T., Chochia A., eds. Brexit: History, Reasoning and Perspectives. London, SpringerLink, 2018.300 p. DOI: 10.1007/9783-319-73414-9.

9. Brussels Draws up Plans for More 'MultiSpeed'Post-Brexit EU-27. URL: https:/www.ft.com/ content/c56f99de-fdda-11e6-8d8e-a5e3738f9ae4 (accessed 2 May 2020).

10. Bulmer S., Paterson W.E. Germany As the EU's Reluctant Hegemon? Of Economic Strength and Political Constraints. Journal of European Public Policy, 2013, no. 20 (10), pp. 1387-1405. DOI: 10.1080/ 13501763.2013.822824.

11. Cameron Defies Tory Right Over EU Referendum. Prime Minister, Buoyed by Successful Negotiations on Eurozone Banking Reform, Rejects «In or Out» Referendum on EU. URL: https://www. theguardian.com/politics/2012/jun/29/cameron-no-eureferendum (accessed 2 May 2020).

12. Chopin T., Lequesne C. Differentiation As a Double-Edged Sword: Member States' Practices and Brexit. International Affairs, 2016, vol. 92, no. 3, pp. 531-545.

13. Cini M., Pérez-Solórzano Borragán N. European Union Politics. Oxford, Oxford University Press, 2016. 471 p. DOI: 10.1093/hepl/9780198806530. 001.0001 .

14. Dyson K., Sepos A. Differentiation As Design Principle and As Tool in the Political Management of European Integration. Which Europe? The Politics of Differentiated Integration. Basingstoke, Palgrave, 2010, pp. 3-23.

15. European Council Herman Van Rompuy. Brussels, 26 June 2012 EUCO 120/12 PRESSE 296 PR PCE 102. URL: https://www.consilium.europa.eu/ media/21570/131201.pdf(accessed 2 May 2020).

16. Holzinger K. EU Environmental Policy in the Joint-Decision Trap? The Critical Balance Between Negative and Positive Integration. Falkner G., ed. Exits from the Joint-Decision Trap: Comparing EU Policies. Oxford, Oxford University Press, 2011, pp. 110-127. 
17. Holzinger K., Schimmelfennig F. Differentiated Integration in the European Union Many Concepts, Sparse Theory, Few Data. Journal of European Public Policy, 2012, vol. 19, iss. 2, pp. 292-305. DOI: 10.1080/ 13501763.2012.641747.

18. Jensen C.B., Slapin J.B. The Politics of Multispeed Integration in the European Union. Richardson J., Mazey S., eds. European Union: Power and Policy-Making. London, Routledge, 2015, pp. 6380. DOI: $10.4324 / 9781315735399$.

19. José Manuel Durão Barroso, President of the European Commission. Presentation of European Commission Work Programme 2012 SPEECH/11/755, European Parliament. Strasbourg, 15 November 2011. URL: http://europa.eu/rapid/press-release SPEECH-11-755 en.htm (accessed 2 May 2020).

20. Komisarz UE: strefa euro potrzebuje własnego parlamentu. URL: http://biznes.onet.pl/wiadomosci/ue/ parlament-eurolandu-jesli-powstanie-budzet-strefyeuro-moscovici/hszb3g (accessed 2 May 2020).

21. Krotz U., Schild J. Back to the Future? FrancoGerman Bilateralism in Europe's Post-Brexit Union. Journal of European Public Policy, 2018, vol. 25, iss. 8, pp. 1174-1193. DOI: 10.1080/13501763.2018.1467951.

22. Lang K.-O. Die Visegrád-Staaten und der Brexit: im östlichen Mitteleuropa herrscht Sorge angesichts des britischen EU-Austritts. SWP-Aktuell, 2016, no. 53, pp. 1-4. URL: https://www.ssoar.info/ ssoar/bitstream/handle/document/47800/ssoar-2016lang-Die_Visegrad-Staaten_und_der_Brexit.pdf; jsessionid $=287$ A729186FBD560B08CF269D575F6BB? sequence $=1$ (accessed 2 May 2020).

23. Lettre commune de m. Nicolas Sarkozy, Président de la République, et mme Angela Merkel, Chancelière de la République Fédérale d'Allemagne, adressée à m. Herman van Rompuy, Président du Conseil Européen, sur les mesures en faveur du renforcement de la zone euro, le 7 décembre 2011. 7 décembre 2011. URL: https://www.elysee.fr/nicolassarkozy/2011/12/07/lettre-commune-de-m-nicolas-sarkozypresident-de-la-republique-et-mme-angela-merkelchanceliere-de-la-republique-federale-dallemagneadressee-a-m-herman-van-rompuy-president-du-conseileuropeen-sur-les-mesures-en-faveur-du-renforcement-dela-zon (accessed 2 May 2020).

24. Majone G. Europe As the Would-Be WorldPpower. The EU at Fifty. Cambridge, Cambridge University Press, 2009. 266 p.

25. Merkel, Sarkozy Outline Competitiveness Pact. URL: https://www.politico.eu/article/merkelsarkozy-outline-competitiveness-pact/ (accessed 2 May 2020).

26. Moravcsik A. Preferences and Power in the European Community. A Liberal Intergovernmentalist Approach. Journal of Common Market Studies, 1993, no. 31 (4), pp. 473-524.
27. Mr Major's Speech in Leiden. 1994. Sep. 7. URL: http://www.iohnmaior.co.uk/page1124.html (accessed 2 May 2020).

28. Niemcy popieraja Europę dwóch prędkości. URL: http://www.newsweek.pl/swiat/europa-dwochpredkosci,artykuly,406496,1.html (accessed 2 May 2020).

29. Réformes de la zone euro: pourquoi la réunion entre Macron et Merkel à Berlin est cruciale. URL: https://www.lemonde.fr/europe/article/2018/04/ 19/reformes-de-la-zone-euro-pourquoi-la-reunionentre-macron-et-merkel-a-berlin-est-cruciale 5287737_3214.html (accessed 2 May 2020).

30. Schimmelfennig F. The Choice for Differentiated Europe: An Intergovernmentalist Theoretical Framework. Comparative European Politics, 2019, February, pp. 176-191.DOI: 10.1057/s41295-019-00166-5.

31. Schmidt V. The Future of Differentiated Integration: A 'Soft-Core' Multi-Clustered Europe of Overlapping Policy Communities. Comparative European Politics, 2019, vol. 17, iss. 2, pp. 294-315. DOI: 10.1057/s41295-019-00164-7.

32. Stubb A. The 1996 Intergovernmental Conference and the Management of Flexible Integration. Journal of European Public Policy, 1997, no. 4 (1), pp. 37-55. DOI: 10.1080/135017697344226.

33. Stubb A. A Categorization of Differentiated Integration. Journal of Common Market Studies, 1996, no. 34 (2), pp. 283-295. DOI: 10.1111/j.1468-5965.1996. tb00573.x.

34. Stubb A. Negotiating Flexibility in the European Union: Amsterdam, Nice and Beyond. London, Palgrave MacMillan, 2002, XIV. 218 p. DOI: 10.1057/9781403907615.

35. Tosiek P. Scenariusze rozwoju Unii Europejskiej w ujęciu liberalnej międzyrzqdowości. Integracja Europejska - Polska perspektywa. Warszawa, Wydawnistwo sejmowe, 2018, pp. 283-303.

36. Towards a Genuine Economic and Monetary Union. Report by President of the Why Nordic Countries are a Cornerstone of British Foreign Policy. URL: http://www.nouvelle-europe.eu/en/whynordic-countries-are-cornerstone-british-foreignpolicy (accessed 2 May 2020).

37. Warleigh A. Flexible Integration: Which Model for the European Union? London, Sheffield Academic Press, 2002. 144 p.

38. Webber D. Trends in European Political (Dis)integration. An Analysis of Postfunctionalist and Other Explanations. Journal of European Public Policy, 2019, vol. 26, iss. 8: Special Issue: Re-Engaging Grand Theory: European Integration in the Twenty-First Century, pp. 1134-1152. DOI: 10.1080/13501763.2019.1576760.

39. Wilding P. Stumbling Towards the Brexit. Britain, a Referendum and an Ever-Closer Reckoning. URL: https://blogactiv.eu/blog/2012/05/15/stumblingtowards-the-brexit/ (accessed 2 May 2020). 


\section{ИСТОРИЯ МЕЖДУНАРОДНЫХ ОТНОШЕНИЙ}

\section{Information About the Author}

Dmitriy V. Ofitserov-Belskiy, Candidate of Sciences (History), Associate Professor, Senior Researcher, Primakov Institute of World Economy and International Relations of the Russian Academy of Sciences, Profsoyuznaya St, 23, 117997 Moscow, Russian Federation, DmitriyBelskiy@gmail.com, https://orcid.org/0000-0002-5892-9117

\section{Информация об авторе}

Дмитрий Владимирович Офицеров-Бельский, кандидат исторических наук, доцент, старший научный сотрудник Центра постсоветских исследований, Институт мировой экономики и международных отношений им. Е.М. Примакова РАН, ул. Профсоюзная, 23, 117997 г. Москва, Российская Федерация, DmitriyBelskiy@gmail.com, https://orcid.org/0000-0002-5892-9117 